\title{
Doctors' attitudes to risk in difficult clinical decisions: application of decision analysis in hepatobiliary disease
}

\author{
A THEODOSSI, D J SPIEGELHALTER, I G McFARLANE, ROGER WILLIAMS
}

\begin{abstract}
Twelve doctors with special training in hepatology independently reviewed two to five cases each from a group of seven cases of complicated hepatobiliary problems. A doctor's willingness to take risks to improve his patients' health was quantified by a wagering technique based on the probability of achieving a successful intervention. These probabilities were then used to calculate "utilities," which represented the average opinion of the doctors about the relative worth of each of six predefined states of health. The results showed that, in the context of risky decisions for severely ill patients, a year of life was considered by the doctors to be worth $44 \%$ of a full recovery; being mobile for that year increased this value to $57 \%$. Survival for up to five years with restricted mobility was considered to be worth $70 \%$ of a full recovery ${ }^{1}$ and the ability to work during that period increased this value to $85 \%$.

It is concluded that in clinical decision making the uncertainty and preferences implicit in a course of action can be quantified and thus made explicit.
\end{abstract}

\section{Introduction}

One of the most difficult decisions faced by a doctor concerns the choice, in the case of a seriously ill patient, of whether to intervene if failure of the intervention might result in an even worse prognosis. In hepatobiliary disease such a choice may be about giving specific treatment with known side effects or carrying out further, perhaps invasive, diagnostic techniques.

Liver Unit, King's College Hospital and Medical School, London SE5 A THEODOSSI, MB, MRCP, clinical research fellow I G MCFARLANE, PHD, consultant biochemist ROGER WILLIAMS, MD, FRCP, director

MRC Biostatistics Unit, MRC Centre, Cambridge D J SPIEGELHALTER, PHD, statistician

Correspondence to: Dr A Theodossi, Westminster Hospital, London SW1P 2AP.
In making the decision the physician has to take account, firstly, of the likelihood of success if he does intervene and, secondly, of the relative merits of the three possible outcomesnamely, success or failure of the intervention or maintenance of the status quo if he decides not to intervene. In such circumstances doctors have always relied on clinical judgment, ${ }^{1-3}$ and some clinicians seem to have an innate ability to choose the optimum course of action. Others learn by experience, either by emulating their seniors or through facing similar difficult decisions repeatedly during their careers.

A more formal approach is the use of decision analysis. ${ }^{45}$ This entails separating a complex decision problem into its component parts, for each of which a point may be defined at which either one of a choice of actions must be selected or one of a number of events must occur. Any uncertainty about the occurrence of an event is expressed numerically as a probability (p), while the decision maker's preference for each possible consequence (defined in this context as a "state of health") is quantified as a utility $(U)$, with a numerical value being assigned to each of the possible consequences of the decision. Thus the ill defined concept of "risk" is explicitly divided between two components-namely, the likelihood of a poor outcome and the relative value of the consequences of that poor outcome should it occur. By distinguishing between these two aspects of a serious clinical decision it is hoped to increase the likelihood that the decision problem will be carefully evaluated, thereby leading to a considered and consistent judgment based, ideally, on the principle of "maximising expected utility." To make such an analysis based on the assumption that the doctor is the decision maker, the clinicians' utilities for a range of states of health must first be estimated. Therefore, we undertook the present study in hepatobiliary disease to quantify doctors' willingness to take risks to improve the health of patients, and thereby to identify numerical values reflecting the worth of each of several defined states of health as implicitly perceived by a clinician facing a difficult decision.

\section{Methods}

We selected seven cases of hepatobiliary disease on the basis that in each case a difficult decision had had to be made on whether to intervene clinically because the intervention might have resulted 
either in considerable improvement or in deterioration in the patient's state of health. Twelve clinicians, all with specialist training (for two to eight years) in hepatobiliary disease, were presented with a selection of up to five cases for assessment, resulting in a total of 45 decisions. Only cases for which the clinician believed that he could give a confident, unbiased judgment were included for analysis.

\section{EVALUATION OF SUCCESS RATES AND UTILITIES}

For each case the doctor was asked to review the patient's history, make a decision on whether to intervene, and state the percentage chance of success (the "success rate") of the intervention that he would require before agreeing to take the associated risk. To obtain this value a "wagering" technique was used: the doctor was asked in sequence whether he would intervene if there was a $95 \%$ chance of success; if yes, whether he would intervene if there was a $20 \%$ chance; if no, whether he would consider $90 \%$ acceptable; and so on until an "indifference point" (expressed as a percentage) was reached, at which the clinician was unable to choose between the potential benefits of a successful intervention and the risk of a failed intervention.

The clinician was then shown a decision tree (figure), in which (at the indifference point) the success rate is expressed as a probability (p) and the failure rate, by definition, as $1-\mathrm{p}$, and was asked to assign prognoses to each of the three possible outcomes-that is, $U_{q}, U_{t}$, and $U_{s} \multimap$ of the decision. As this meant defining each of the outcomes in terms of disability and life expectancy the doctor was also asked to state how long he would expect the patient to live and the patient's expected state of health. If he stated that any of the three outcomes could be associated with more than one prognosis the wagering technique was used to determine his opinion of the likelihood of occurrence (as a percentage) of these additional prognoses. These were then incorporated into the same decision tree. Finally, the clinician was asked whether he wished to change his original required success rate.

At the end of this assessment each clinician was asked to comment on whether he had found the sample cases realistic and for his opinion on the merits of setting out such a formal decision tree.

\section{CALCULATION OF UTILITIES}

Every prognosis assessed by the doctors was classified by two of us (AT, DS) into one of six states of health (table I) that had been defined before the study; these had not been communicated to the clinicians to avoid influencing their assessments. Of these six states

TABLE I-States of health and their estimated utilities

\begin{tabular}{llc}
\hline & \multicolumn{1}{c}{ States of health } & Utility \\
(SE)
\end{tabular}

of health, 1 and 6 were the worst and best possible prognoses respectively and were assigned utility values of 0 and 100 , these being arbitrary end points relative to which the intermediate states are assessed. To determine corresponding values $\left(U_{2}\right.$ through to $\left.U_{5}\right)$ for the four remaining states of health the success rates and prognoses assessed by each doctor for each case were inserted in the following equation (derived from the figure):

$$
\left.\left(p \times U_{s}\right)+(1-p) \times U_{\mathrm{f}}=U_{q} \quad \text { (equation } 1\right)
$$

in which, according to decision theory, at the indifference point the product of the probability $(p)$ and the utility $\left(U_{s}\right)$ of a successful intervention plus the product of the probability $(1-p)$ and utility $\left(U_{f}\right)$ of a failed intervention is equal to the utility $\left(U_{q}\right)$ of the status quothat is, the expected utility of intervention is equal to the expected utility of the status quo.

The 45 equations so derived (one for each decision) were subjected to least squares analysis (a form of multiple regression) ${ }^{6}$ to obtain values for $U_{2}$ to $U_{5}$ that provided the closest possible predictions of

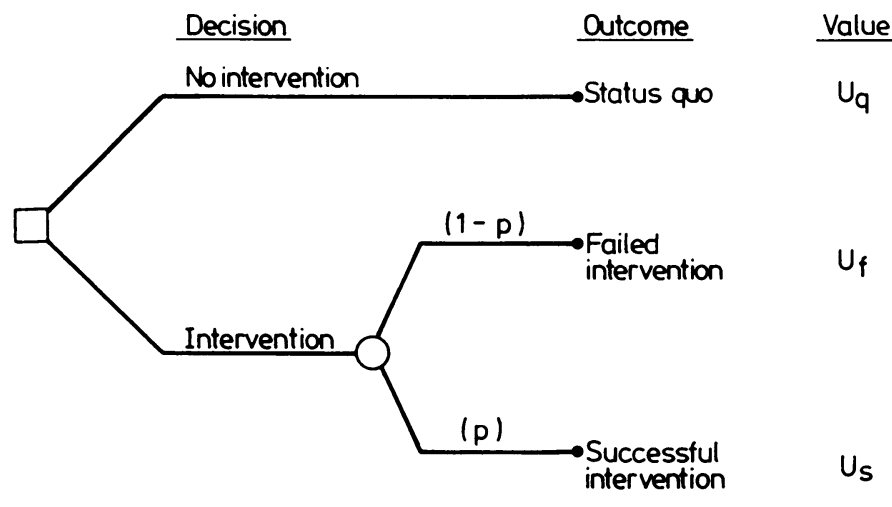

A decision tree showing two available options-namely, intervention and non-intervention. The square denotes the decision, and the circle the uncertainty about success or failure of intervention.

the clinicians' opinions about acceptable risks and therefore represented the "average" opinion on the relative worth of each of states of health 2 to 5 . The least squares procedure also provided a check that it was reasonable to adopt such an average view (that is, that the clinicians did not vary significantly between each other in their feelings about reasonable risks to take) and provided standard errors for the resulting estimates of average utilities. The average utilities were then used to calculate, for each decision, the success rate $p_{s}$, which would be demanded by formal decision analysis, by solving the following equation for the given prognosis:

$$
\begin{gathered}
\mathrm{U}_{\mathrm{q}}=\left(1-\mathrm{p}_{\mathrm{s}}\right) \mathrm{U}_{\mathrm{l}}+\left(\mathrm{p}_{\mathrm{s}} \times \mathrm{U}_{\mathrm{s}}\right) \\
\text { that is, } \mathrm{p}_{\mathrm{s}}=\frac{\mathrm{U}_{\mathrm{q}}-\mathrm{U}_{\mathrm{l}}}{\mathrm{U}_{\mathrm{s}}-\mathrm{U}_{\mathrm{l}}} \quad \text { (equation 2) }
\end{gathered}
$$

\section{Results}

Table II gives the diagnoses and particular management problems in the seven cases selected. All cases had been fully evaluated in the liver unit by clinical staff who were not members of the panel used in this study, and the interventions that had been contemplated were

\begin{tabular}{|c|c|c|c|c|}
\hline $\begin{array}{l}\text { Case } \\
\text { No }\end{array}$ & $\begin{array}{l}\text { Age } \\
\text { (years) }\end{array}$ & Sex & $\begin{array}{l}\text { Diagnosis and } \\
\text { management problem }\end{array}$ & $\begin{array}{l}\text { Contemplated } \\
\text { intervention }\end{array}$ \\
\hline 1 & 60 & $\mathbf{M}$ & $\begin{array}{l}\text { Secondary biliary cirrhosis due } \\
\text { to retained bile duct stones } \\
\text { after cholecystectomy. }\end{array}$ & $\begin{array}{c}\text { Surgical relief of } \\
\text { obstruction }\end{array}$ \\
\hline 2 & 28 & $\mathbf{F}$ & $\begin{array}{l}\text { Budd-Chiari syndrome with } \\
\text { short history of ascites and } \\
\text { encephalopathy }\end{array}$ & $\begin{array}{l}\text { Side to side portacaval } \\
\text { anastomosis }\end{array}$ \\
\hline 3 & 49 & $\mathbf{F}$ & End stage primary biliary & Liver transplantation \\
\hline 4 & 45 & $\mathbf{F}$ & Jaundice with fever due to & Surgical drainage \\
\hline 5 & 60 & $\mathbf{M}$ & $\begin{array}{l}\text { Bleeding oesophageal varices } \\
\text { from cryptogenic cirrhosis }\end{array}$ & Oesophageal transection \\
\hline 6 & 28 & $\mathbf{F}$ & $\begin{array}{l}\text { Long standing sclerosing } \\
\text { cholangitis with deep jaundice }\end{array}$ & Liver transplantation \\
\hline 7 & 62 & $\mathbf{M}$ & $\begin{array}{l}\text { Ischaemic heart disease. } \\
\text { Acute pancreatitis and recent } \\
\text { septicaemia with numerous } \\
\text { stones in gall bladder and } \\
\text { common bile duct }\end{array}$ & $\begin{array}{l}\text { Cholecystectomy and } \\
\text { exploration of common } \\
\text { bile duct }\end{array}$ \\
\hline
\end{tabular}
considered to have been the most feasible option in each instance.

TABLE II-Summary of diagnoses and management problems in the seven cases

USE OF A DECISION TREE IN A SPECIFIC INSTANCE (CASE 1, TABLE II)

A 60 year old man, with secondary biliary cirrhosis due to retained stones in the common bile duct after cholecystectomy 25 years previously, presented with recurrent bouts of abdominal pain, fever, and jaundice. Liver function tests showed an obstructive picture, which was confirmed by liver biopsy, which also indicated probable cirrhotic transformation. Percutaneous cholangiography showed several stones in the biliary tree, which were impacted at the junction 
of the common bile duct and common hepatic duct. The stones were too large (up to $3 \mathrm{~cm}$ in diameter) to be removed by endoscopic sphincterotomy, and operation was risky in view of the adhesions, high obstruction of the duct, and possibility of bleeding due to associated portal hypertension.

Using the decision tree, clinician A (table III) assessed that (a) without operation (that is, in the status quo) the patient would probably remain mobile but die within a year (state 3 , table I); (b) a failed operation would lead to perioperative death (state 1); and (c) although the probable secondary biliary cirrhosis would lead to some shortening of life expectancy, a successful operation would return the patient to virtually normal health (state 6). Using the wagering technique, the clinician stated that if there were a $75 \%$ chance of success $(p=0.75)$ he would find it impossible to choose between "operate" and "not operate." Applying equation 1 ,

$$
\mathrm{U}_{\text {state }{ }_{3}} \approx\left(0.25 \times \mathrm{U}_{\text {state }}\right)+\left(0.75 \times \mathrm{U}_{\text {state }}\right)
$$

Exact equality cannot be expected as there will obviously not be exact agreement between our model of rational decision making and actual judgments.

As $U_{1}$ and $U_{6}$ had the predefined values of 0 and 100 respectively the equation could be solved for the one unknown utility, $\mathrm{U}_{3}$, to quantify this doctor's attitude about this state of health. Solution of the equation showed that $\mathrm{U}_{3} \approx 75 \%$-that is, this doctor believed that a year of life with restricted mobility was worth about $75 \%$ of a full recovery. By comparison, clinician $B$ gave a similar assessment of the case but his indifference point was $65 \%(\mathrm{p}=0.65)$. Applying this $\mathrm{p}$ value to the above equation showed that $\mathrm{U}_{3} \approx 65 \%$-that is, in the opinion of clinician B the same state of health was worth only about $65 \%$ of the value of full recovery. Other equations could not be solved so simply. For example, for this decision clinician $\mathrm{F}$ stated that an $80 \%$ chance of state 3 and a $20 \%$ chance of state 5 "was approximately equivalent" to a $60 \%$ chance of state 6 and a $40 \%$ chance of state 1 :

$$
0.80 \mathrm{U}_{3}+0.20 \mathrm{U}_{5} \approx 0.40 \mathrm{U}_{1}+0.60 \mathrm{U}_{6}
$$

Least squares analysis simply estimated the values of $U_{2}$ to $U_{5}$ that minimised the sum of the squared differences between the left and right hand sides of the $\mathbf{4 5}$ equations.

\section{ANALYSIS OF THE 45 DECISIONS IN THE SEVEN CASES}

Excellent agreement between the clinicians was found with regard to the likely prognosis after intervention (table III), but there was inevitably some divergence of opinion about prognoses of the status quo. When this occurred the divergent view was often balanced by the doctor requiring an appropriately higher or lower success rate than his colleagues. Thus, clinician $K$ in case 6 was pessimistic about the outcome without intervention and required a success rate of only $40 \%$ while clinician $\mathrm{C}$, in the same case, was optimistic and wanted a $90 \%$ success rate before agreeing to intervene.

Least squares analysis of the 45 decisions yielded the average utilities shown in table I. Allowing individual utilities for each clinician did not provide a significantly better fit to the data $\left(\mathrm{F}_{33},{ }_{8}=0.61, \mathrm{NS}\right)$. By using equation 2 it is possible to calculate the theoretical success rates $\left(\mathrm{p}_{\mathrm{s}}\right)$ that a clinician would demand were he using the consensus utility values and behaving "rationally" in the technical sense of maximising expected utility. When the clinicians were considered as a group their stated success rates required for each case showed fairly good agreement with the calculated $\left(p_{s}\right)$ values (table IV), but calculation of these values on an individual basis showed inconsistencies (table III). Thus in 19 of the 45 decisions

\begin{tabular}{|c|c|c|c|c|c|}
\hline \multirow[b]{2}{*}{ Physician } & \multicolumn{3}{|c|}{ States of health } & \multirow[b]{2}{*}{$\begin{array}{l}\text { Required \% success rate } \\
\text { (p) }\end{array}$} & \multirow[b]{2}{*}{$\begin{array}{c}\text { Calculated } * \% \text { success rate } \\
\left(\mathrm{p}_{s}\right)\end{array}$} \\
\hline & $\begin{array}{c}\text { If no intervention } \\
\left(U_{q}\right)\end{array}$ & $\begin{array}{c}\text { If intervention failed } \\
\left(U_{f}\right)\end{array}$ & If intervention succeeded & & \\
\hline \multicolumn{6}{|l|}{ Case 1} \\
\hline A & 3 & 1 & 6 & 75 & 57 \\
\hline B & 3 & 1 & 6 & 65 & 57 \\
\hline $\mathrm{D}$ & 4 & 1 & 6 & 60 & 70 \\
\hline $\mathrm{F}$ & $3(80 \%)+5(20 \%)$ & 1 & 6 & 60 & 63 \\
\hline $\mathrm{H}$ & 3 & 1 & 6 & 65 & 57 \\
\hline$\stackrel{\mathrm{I}}{\mathrm{K}}$ & $\begin{array}{l}4 \\
2\end{array}$ & 1 & $\begin{array}{l}6 \\
5\end{array}$ & 75 & $\begin{array}{l}70 \\
51\end{array}$ \\
\hline$\hat{\mathrm{L}}$ & 4 & 1 & 6 & 85 & $\begin{array}{l}31 \\
70\end{array}$ \\
\hline \multicolumn{6}{|l|}{ Case 2} \\
\hline A & 2 & 1 & 6 & 50 & 44 \\
\hline$\stackrel{B}{G}$ & 2 & 1 & 6 & 65 & 44 \\
\hline \multicolumn{6}{|l|}{ Case 3} \\
\hline A & $2(50 \%)+3(50 \%)$ & 1 & $6(40 \%)+4(60 \%)$ & 70 & 62 \\
\hline$\stackrel{B}{\mathrm{~B}}$ & 2 & 1 & 5 & 25 & 51 \\
\hline C & 3 & $\begin{array}{l}1 \\
1\end{array}$ & $\begin{array}{l}5 \\
6\end{array}$ & $\begin{array}{l}50 \\
50\end{array}$ & $\begin{array}{l}67 \\
57\end{array}$ \\
\hline E & 3 & 1 & 5 & 60 & 67 \\
\hline $\mathrm{F}$ & 3 & 1 & 5 & 50 & 67 \\
\hline $\mathrm{G}$ & $\begin{array}{l}4 \\
2\end{array}$ & 1 & $\begin{array}{l}5 \\
5\end{array}$ & $\begin{array}{l}50 \\
30\end{array}$ & 82 \\
\hline I & $\begin{array}{l}2 \\
4\end{array}$ & 1 & $\begin{array}{l}3 \\
5\end{array}$ & $\begin{array}{l}30 \\
75\end{array}$ & $\begin{array}{l}51 \\
82\end{array}$ \\
\hline $\mathrm{J}$ & 3 & 1 & 5 & 70 & 67 \\
\hline $\mathrm{K}$ & 4 & i & 5 & 70 & 82 \\
\hline \multicolumn{6}{|l|}{ Case 4} \\
\hline $\mathrm{B}^{-1}$ & 2 & 1 & 6 & 40 & 44 \\
\hline \multirow{2}{*}{\multicolumn{6}{|c|}{ Case 5}} \\
\hline & & & & & \\
\hline $\begin{array}{l}\mathbf{A} \\
\mathbf{B}\end{array}$ & $\begin{array}{l}3(60 \%)+6(40 \%) \\
3(95 \%)+5(5 \%)\end{array}$ & $1(25 \%)+3(75 \%)$ & 5 & 70 & 87 \\
\hline C & $\begin{array}{c}5 \\
0\end{array}$ & $1(25 \%)+3(13 \%)$ & $\begin{array}{l}5 \\
5\end{array}$ & 50 & $\begin{array}{l}37 \\
51\end{array}$ \\
\hline $\mathrm{D}$ & 3 & 1 & 5 & 60 & 67 \\
\hline $\mathrm{F}$ & 3 & 1 & 5 & 65 & 67 \\
\hline$\underset{\mathrm{H}}{\mathrm{G}}$ & $\begin{array}{l}2 \\
4\end{array}$ & 1 & $\begin{array}{r}5 \\
5\end{array}$ & 80 & 51 \\
\hline I & $\begin{array}{l}4 \\
3\end{array}$ & 1 & $\begin{array}{l}5 \\
4\end{array}$ & $\begin{array}{l}90 \\
90\end{array}$ & $\begin{array}{l}82 \\
81\end{array}$ \\
\hline $\mathrm{K}$ & 2 & 1 & 6 & 40 & 44 \\
\hline $\mathrm{L}$ & 2 & $i$ & 4 & 75 & 63 \\
\hline \multicolumn{6}{|l|}{ Case 6} \\
\hline A & $3(40 \%)+4(30 \%)+5(30 \%)$ & 1 & $5(60 \%)+6(40 \%)$ & 80 & 76 \\
\hline C & $\begin{array}{l}5 \\
4\end{array}$ & 1 & $\begin{array}{l}6 \\
6\end{array}$ & 90 & 86 \\
\hline $\mathrm{E}$ & 4 & 1 & $\begin{array}{l}\mathbf{0} \\
5\end{array}$ & $\begin{array}{l}90 \\
85\end{array}$ & 82 \\
\hline $\mathrm{F}$ & 4 & 1 & 5 & 85 & 82 \\
\hline $\mathrm{H}$ & $\begin{array}{l}4 \\
4\end{array}$ & 1 & $\begin{array}{l}5 \\
5\end{array}$ & $\begin{array}{l}80 \\
85\end{array}$ & $\begin{array}{l}82 \\
82\end{array}$ \\
\hline $\mathrm{K}$ & 2 & 1 & 5 & 40 & $\begin{array}{l}82 \\
51\end{array}$ \\
\hline $\mathrm{L}$ & 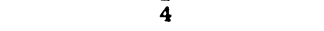 & 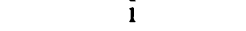 & & 80 & 82 \\
\hline \multicolumn{6}{|l|}{ Case 7} \\
\hline H & $\begin{array}{l}4 \\
5\end{array}$ & 1 & 6 & 80 & 70 \\
\hline J & 5 & 1 & 6 & 75 & 86 \\
\hline
\end{tabular}

TABLE III-Success rates and states of health for the 45 decisions

- $p$, was calculated from equation 2 and the consensus utilities in table I. 
the success rate required by the clinicians deviated by more than $10 \%$ from the corresponding $\mathrm{p}_{\mathrm{s}}$ value. The residual standard deviation from the least squares analysis was 13, suggesting that use of the average utilities and equation 2 will predict a doctor's willingness to take risks to that margin of error.

TABLE IV-Comparison of success rates calculated with formal decision analysis and mean success rates required by the doctors

\begin{tabular}{|c|c|c|c|c|c|c|}
\hline \multirow{2}{*}{$\begin{array}{l}\text { Decision } \\
\text { (case) } \\
\text { No }\end{array}$} & \multirow[b]{2}{*}{$\begin{array}{c}\text { No of } \\
\text { doctors }\end{array}$} & \multicolumn{3}{|c|}{ Mean utility values* } & \multirow{2}{*}{$\begin{array}{l}\text { Mean }(\mathrm{SE}) \text { success } \\
\text { rates required }(\mathrm{p})^{*} \\
(\%)\end{array}$} & \multirow{2}{*}{$\begin{array}{c}\text { Calculated success } \\
\text { rates }\left(\mathrm{p}_{\mathrm{s}}\right) \dagger \\
(\%)\end{array}$} \\
\hline & & $\overline{\mathrm{U}}_{\mathrm{q}}$ & $\overline{\mathrm{U}}_{\mathrm{t}}$ & $\overline{\mathrm{U}}_{\mathrm{s}}$ & & \\
\hline $\begin{array}{l}1 \\
2 \\
3 \\
4 \\
5 \\
6 \\
7\end{array}$ & $\begin{array}{r}8 \\
3 \\
11 \\
2 \\
10 \\
9 \\
2\end{array}$ & $\begin{array}{l}61 \\
44 \\
58 \\
44 \\
55 \\
69 \\
78\end{array}$ & $\begin{array}{l}0 \\
0 \\
0 \\
0 \\
4 \\
0 \\
0\end{array}$ & $\begin{array}{r}98 \\
100 \\
86 \\
100 \\
81 \\
89 \\
100\end{array}$ & $\begin{array}{lr}71 & (3 \cdot 3) \\
48 & (10 \cdot 1) \\
55 & (5 \cdot 0) \\
33 & (7 \cdot 5) \\
70 & (5 \cdot 1) \\
79 & (5 \cdot 1) \\
78 & (2 \cdot 5)\end{array}$ & $\begin{array}{l}62 \\
44 \\
67 \\
44 \\
66 \\
78 \\
78\end{array}$ \\
\hline
\end{tabular}

* Calculated from data in tables I and III.

+Calculated from equation 2 , using the mean utility values $\bar{U}_{q}, \bar{U}_{f}$, and $\bar{U}_{s}$.

\section{DOCTORS' OPINIONS OF DECISION ANALYSIS}

The doctors stated that the seven sample cases were realistic and that they had encountered similar problems previously. Predictably, their main difficulties related to attaching numbers to success rates and prognosis. Care must be taken in the way the questions are worded, as responses differ depending on whether questions are asked in terms of "survival rates" or "death rates." I In addition, it was fairly time consuming to obtain satisfactory interviews, but, using the wagering technique and decision trees, the clinicians were in general able to give appropriate numbers. All 12 doctors stated that use of the decision trees had encouraged them to assess more deliberately the risks and benefits of an intervention, although two questioned whether patients whose problems were subjected to decision analysis would fare any better than those for whom conventional clinical evaluation was used. After using the decision trees doctors changed their required success rates in four instances and, in two others, changed their original decisions from not intervening to operating on the patient.

\section{Discussion}

The present study shows that, even though they are not accustomed to so doing, doctors can explicitly attach numerical values to the chance of occurrence of an event (probability) and that these values can be used to determine implicit utilities for different states of health. Other studies have measured utilities for length of lif $^{8}$ and visual acuity, ${ }^{9}$ and use of utilities has been recommended in decisions concerning coronary artery bypass surgery, ${ }^{10}$ genetic counselling, ${ }^{11}$ selection of further investigatory tests, ${ }^{12}$ and treatment of breast cancer. ${ }^{13}$ Clinicians' assessments of the seriousness of errors in the diagnosis of jaundice have also been determined. ${ }^{14}$ The "consensus" utilities show several interesting facets to the attitudes of our panel of clinicians. The value of 44 obtained for state 2 (one year survival, immobile) says, in effect, that this particular group of doctors assessed an extra year of life to be worth $44 \%$ of a full recovery. This relatively high value reflects their undoubted aversion to perioperative death. Nevertheless, quality of life was also clearly important to the panel as the prospect of mobility in that year of life (state 3 ) increased the utility value by almost a third to $57 \%$.

The utility values obtained here could be used as a guide for the individual clinician to the "reasonable" risk to take in a patient with complicated problems of hepatobiliary disease. In practice, the doctor would use the decision tree to assign probabilities and prognoses and then apply to equation 2 the average utility values corresponding to his prognoses, thereby obtaining a $\mathrm{p}_{\mathrm{s}}$ value reflecting the average opinion of a panel of specialists for the prognoses he had defined. Comparison of this value with his required success rate would either reinforce his decision or warn him to reassess his reason for taking a different view. Indeed, this approach was used to examine individual decisions in the present study, and occasional examples of apparent incoherence (relative to the average opinion) were found. The present values, however, were obtained from a panel of doctors in a single clinical unit, and it remains to be determined whether these values are universally applicable to decisions relating to hepatobiliary disease. Furthermore, these "consensus" utilities took account of only two attributes-namely, life expectancy and disability. Other attributes, such as pain, may need to be assessed, and much of this information will have to be obtained from the patients. It will also be important to determine whether patients' preferences for different states of health mirror those of the clinicians in this study, as the patient's preference for a particular outcome should be regarded as the crucial factor in influencing a decision. ${ }^{15}$ Patients' preferences have been measured and their use illustrated in the selection of treatment of lung $^{8}$ and laryngeal ${ }^{16}$ cancer, and surveys of "utilities" of a general population have been carried out. ${ }^{17}$ Notwithstanding these unresolved questions, we consider that the utilities obtained in the present study are of more value than an assessment of outcomes based purely on survival.

We believe that the present study shows the feasibility of formally applying decisions analysis to clinical practice. The procedures entailed are a useful adjunct to the normal processes of scrupulous assessment of cases required for clinical decision making, particularly in the context of difficult decisions on the management of severely ill patients. The solution to a patient's problem is usually sought by carefully reading through the case notes and specifically asking him or his family about his chief complaints. Although this takes time, it yields information necessary for solution of the problem. This information must, however, be processed, and decision analysis is a logical approach to handling it.

The present study may be viewed as a first step towards measuring the benefit of treatment, particularly in hepatobiliary disease, so that it may be weighed against risk and cost, thereby leading to decisions that are rational in terms of benefit to the patient and the use of resources.

We are indebted to the following clinicians who collaborated with us during the study: $J$ Canalese, $M$ Davies, A Gimson, B A Greenway, B R D MacDougall, F Martius, W M A Melia, J Neuberger, R Sewell, D Westaby, R J Wyke.

\section{References}

${ }^{1}$ Feinstein AR. Clinical judgement. Baltimore: Williams and Wilkins, 1967. 2 Schwartz WB, Gorry AG, Kassirer JP, Easig A. Decision analysis and clinical judgement. Am $\mathcal{F}$ Med 1973;55:459-72.

Elstein AS. Clinical judgement: psychological research and medical practice. Science 1976;194:696-700.

- Lindley D. Making decisions. London: Wiley Interscience, 1971.

Weinstein MC, Fineberg HV. Clinical decision analysis. Philadelphia: Saunders, 1980.

6 Daniel C, Wood FS. Fitting equations to data. New York: Wiley, 1971 McNeil BJ, Pauker SG, Sox HC, Tversky A. On the elicitation of preferences for alternative therapies. N Engl f Med 1982;306:1259-62.

作

lung cancer. N Engl f Med $1978 ; 299: 1397-401$.
Card WI, Rusinkiewicz M, Phillips CI. Utility estimation of a set of states of Card W I, Rusinkiewicz M, Phillips C1.

o Pauker SG. Coronary artery surgery: the use of decision analysis. Ann Intern Med $1976 ; 85: 8-18$.

" Pauker SP, Pauker SG. Prenatal diagnosis: a directive approach to genetic counselling using decision analysis. Yale $\mathcal{F}$ Biol Med 1977;50:275-89.

12 Pauker SG, Kassirer JP. The threshold approach to clinical decision making. N Engl f Med $1980 ; 302: 1109-17$.

${ }^{13}$ Langlands AO, Gore SH, Kerr GM. Should adjuvant chemotherapy be withheld from any patient with operable breast cancer? $B r$ Med 7 1982;285:680-2.

1 Le Minor M, Alperovitch A, Knill-Jones RP. Applying decision theory to medical decision mak

${ }^{5}$ Pauker SG, McNeil GJ. Impact of patient preferences on the selection of therapy.

FChron Dis $1981 ; 34: 77-86$.
16 McNeil BJ, Weichselbaum R, Pauker SG. Tradeoffs between quality and quantity of life in laryngeal cancer. $N$ Engl 7 Med $1981 ; 305: 982-7$.

1 Sackett DL, Torrence GW. The utility of different health states as perceived by the general public. $\mathcal{F}$ Chron Dis $1978 ; 31: 697-704$.

(Accepted 9 April 1984) 